\title{
Correction to: Efficacy of pulsed Nd:YAG laser in the treatment of patients with knee osteoarthritis: a randomized controlled trial
}

\author{
Mohamed Salaheldien Mohamed Alayat ${ }^{1}$ - Tarek Helmy Ahmed Aly ${ }^{2}$. Aly Elsayed Mohamed Elsayed ${ }^{3,4}$. \\ Ammar Suliman Mohamed Fadil ${ }^{1}$
}

Published online: 10 July 2020

(C) Springer-Verlag London Ltd., part of Springer Nature 2020

\section{Correction to: Lasers Med Sci}

$$
\text { https://doi.org/10.1007/s10103-017-2141-x }
$$

The institutional affiliation of Dr. Aly Elsayed Mohamed Elsayed should be as follow:

3 Al-Noor Specialist Hospital, Mecca, Saudi Arabia 4 Department of Physical Medicine, Rheumatology and Rehabilitation, Faculty of Medicine, Suez Canal University, Ismailia-Egypt

Publisher's note Springer Nature remains neutral with regard to jurisdictional claims in published maps and institutional affiliations.

The online version of the original article can be found at https://doi.org/ 10.1007/s10103-017-2141-x

Mohamed Salaheldien Mohamed Alayat mohsalahpt@hotmail.com

1 Department of Physical Therapy, Faculty of Applied Medical Sciences, Umm Al-Qura University, Mecca, Saudi Arabia

2 Radiology Department, Um Al-Qura University Medical Center, Mecca, Saudi Arabia

3 Al-Noor Specialist Hospital, Mecca, Saudi Arabia

4 Department of Physical Medicine, Rheumatology and Rehabilitation, Faculty of Medicine, Suez Canal University, Ismailia, Egypt 